\title{
Study on Automobile Power Battery Management System Design
}

\author{
Weidong Guo
}

School of Automotive Engineering, Nanjing Communications Institute of Technology, Nanjing, 211188, China

Keywords: Electric automobile, Iron phosphate-lithium power battery, Power battery pack management system, System design

\begin{abstract}
Due to western energy crisis in 1970s and 1980s, people have attached more importance to natural energy and meanwhile accelerated the development of new energy technology over the last three decades. A lot of new energies that can replace petroleum and coal and new energy use patterns have emerged in the $21^{\text {st }}$ century. Electric automobile is one of the most typical examples. The electric automobile introduced in this paper uses new iron phosphate-lithium power battery, which not only is green, environmentally friendly and highly safe, but also has advantages in lifetime. This paper designs a set of power battery pack management system for electric automobile around iron phosphate-lithium power battery and analyzes hardware design of upper computer and lower computer in this system in detail.
\end{abstract}

\section{Introduction}

Power battery pack management system mentioned in this paper is designed based on iron phosphate-lithium power battery. It is divided into upper computer and lower computer, both of which use SCM as master control. The overall design emphasizes the acquisition and processing of information data and real-time management of working condition of power battery pack, pays great attention to the safety of hardware circuit and guarantees its strong capacity of resisting disturbance. Meanwhile, it has low cost consumption, high monitoring precision and easy maintenance and can match with energy-saving application of modern electric automobile perfectly.

\section{Introduction to iron phosphate-lithium power battery}

The core content of iron phosphate-lithium power battery is lithium ion battery and its interior mainly includes positive pole, negative pole, diaphragm and electrolyte. It is characterized by certain differences of positive pole, negative pole and electrolyte materials in production process from ordinary battery. Their manufacturing materials are also different. This provides it with properties different from ordinary battery. Iron phosphate-lithium battery is mainly made of iron phosphate-lithium material which is mainly applied to positive and negative poles of the battery. Its negative pole is made of graphite. The diaphragm in the middle is composed of polymer, which has the special performance of obstructing electron but allowing lithium ion to pass.

Iron phosphate-lithium power battery can be applied to electric automobile due to its better properties than ordinary battery. For example, it has absolute advantages in overdischarge resistance, discharge current, safety and service life ${ }^{[1]}$, as shown in table 1. 
Table 1. Table of performance comparison between iron phosphate-lithium power battery and ordinary lithium ion battery

\begin{tabular}{|c|c|c|}
\hline & $\begin{array}{l}\text { Iron phosphate-lithium power } \\
\text { battery }\end{array}$ & Ordinary lithium ion battery \\
\hline Standard voltage (V) & 3.2 & $3.6 \sim 3.8$ \\
\hline Scope of working voltage (V) & $3.0 \sim 3.5$ & $3.0 \sim 4.5$ \\
\hline $\begin{array}{lll}\text { Mass } & \text { specific } & \text { capacity } \\
(\mathrm{Ah} / \mathrm{kg}) & & \\
\end{array}$ & 130 & 180 \\
\hline Mass specific energy (Wh/kg) & $60 \sim 75$ & $90 \sim 110$ \\
\hline $\begin{array}{l}\text { Instantaneous high-current } \\
\text { pulse (A) }\end{array}$ & 20 & 2 \\
\hline Optimal charge rate $(\mathrm{C})$ & $0.5 \sim 1.5$ & $0.2 \sim 0.5$ \\
\hline Working discharge rate (C) & 2 & 1 \\
\hline Maximum discharge rate (C) & 10 & 2 \\
\hline Cycle life (times) & 500 (residual 90\%) & 100 (residual $60 \%$ ) \\
\hline High-current cycle life (times) & 300 (residual 70\%) & 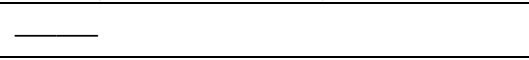 \\
\hline Safety & No combustion and explosion & $\begin{array}{l}\text { Combustion and explosion } \\
\text { might be incurred }\end{array}$ \\
\hline $\begin{array}{l}\text { Zero-voltage storage for } 30 \\
\text { days }\end{array}$ & No damage & $\begin{array}{l}\text { Damage and leakage might } \\
\text { occur }\end{array}$ \\
\hline
\end{tabular}

\section{Hardware design of iron phosphate-lithium power storage battery pack system specific to electric automobile}

The overall system mainly uses a centralized-distributed combining design management scheme. Its principle is overall distribution and partial centralization, as shown in fig.1.

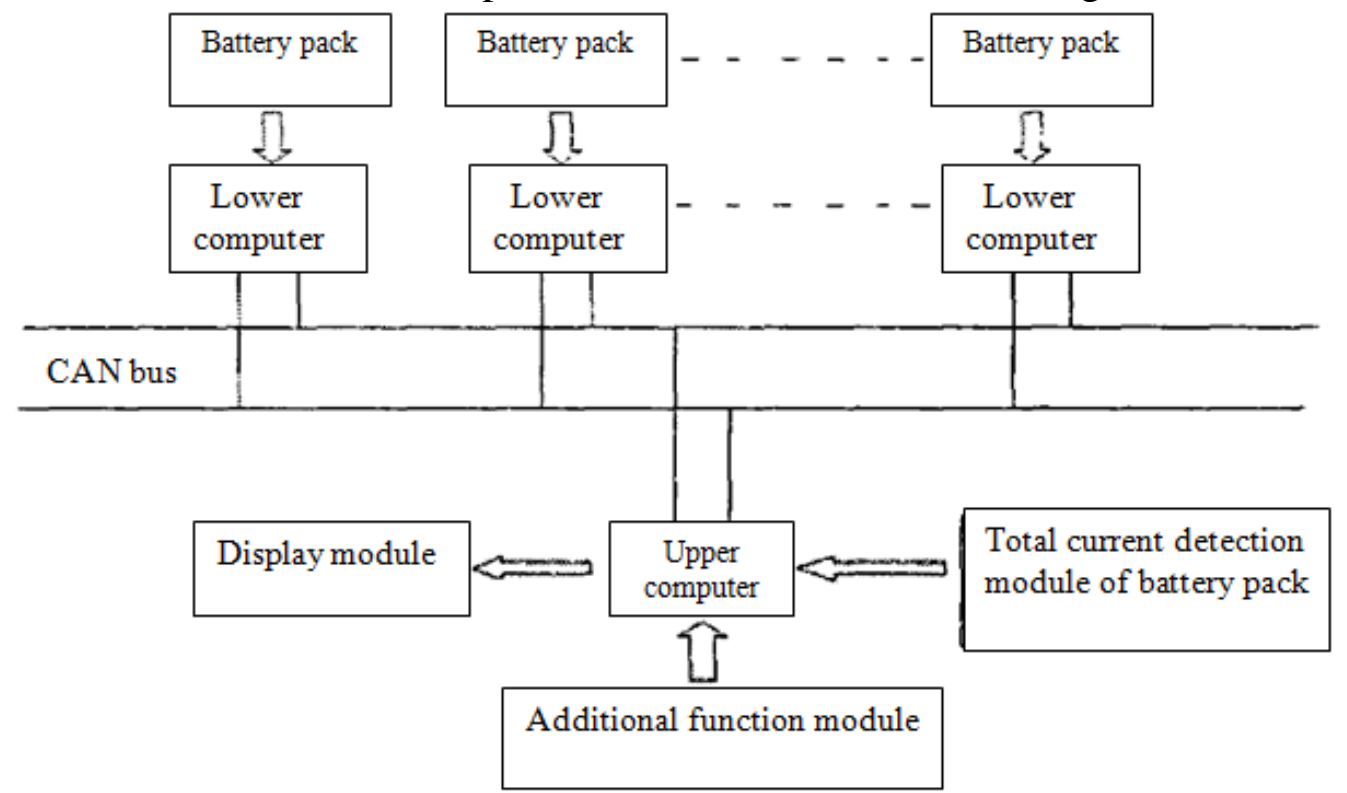

Fig.1 Frame diagram of storage battery pack management system for electric automobile

According to fig.1, 40 to 46 single batteries are required for the operation of power battery pack of electric automobile and should be divided into 3 groups responsible for upper computer and lower computer corresponding to each different part. The purpose is to realize real-time measurement control over the temperature and voltage of single batteries. For example, current monitoring and measurement module is installed in the upper computer part of battery pack. The upper computer is connected to display and can realize remote communication with lower computer via CAN bus. This arrangement is completely due to the consideration of voltage characteristics of battery pack, i.e. 
temperature and voltage signals in the battery pack can be handled at the same time. This is good for cost saving and the improvement of practicability of battery pack.

\section{Working process of battery pack management system}

Working process of the system starts from lower computer. First, it is required to measure the voltage and temperature of single batteries in lower computer and deliver such information to upper computer of the system via CAN bus directly. After receiving current, voltage and temperature test information of battery pack, upper computer will conduct analysis and parametric switch immediately. Then, upper computer processor will estimate the value of SOC of the battery and display available parameters on display screen of the system. In the working process of this management system, 24-hour monitoring of battery voltage and temperature parameters can be realized. Meanwhile, the abnormity of working condition of battery pack can be discovered and alarm processing can be conducted in time. When electric automobile is in running state, the alarm will be raised when SOC value of battery pack is lower than the preset value and the driver will be informed in advance. Drivers can see the charge and discharge information of battery pack on the display screen and its current value will be distinguished with different colors.

\section{Design of minimum system}

Minimum system is a peripheral device control system to be added when processor in battery pack management system is working. This system can be operated under the simplest mode and realize control over power circuit, air, crystal oscillation and reset circuit.

Main design parts in minimum system include external reset circuit and interface circuit of crystal oscillator. If minimum system has run errors such as crash and program run stop, it is required to conduct external reset and power on again. Peripheral reset circuit is required in order to guarantee that reset circuit will not influence the normal work of minimum system, as shown in fig.2.

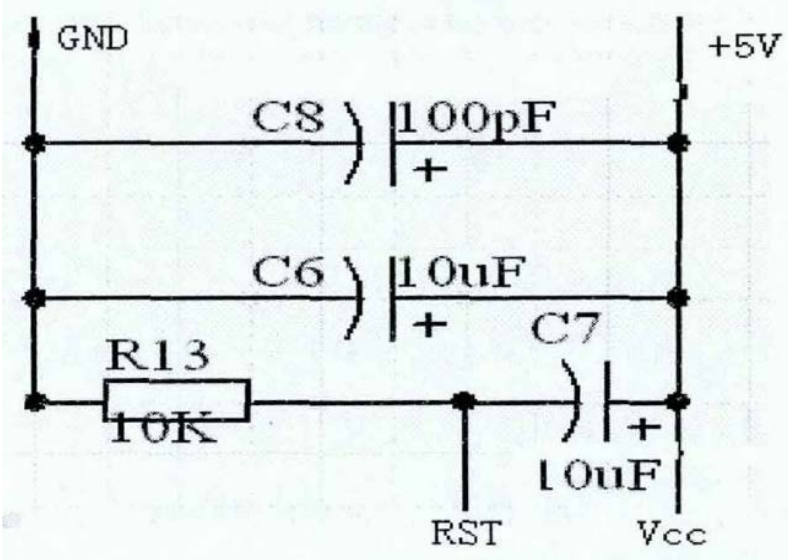

Fig.2 Schematic diagram of SCM reset circuit

Fig. 2 describes the reset circuit of SCM. During its reset, pin RST is used as the foundation of increasing level. It can operate for two or more machine cycles continuously. When it is going to power on, capacitance C7 will charge automatically so that high level at pin RST end can realize reset. When C7 has full charge of capacity, pin RST will return to low level state. C6 and C8 in the figure are mainly responsible for controlling electrical signal filtering in the circuit in order to avoid reset misjudgment while it is power-on. Similarly, if compulsory MCU provided by external RST pin of reset circuit enters reset state in SCM minimum system of lower computer, the addition of effective signal to its pin can produce the same reset effect. At this time, it is necessary to add a RST pin decoupling externally to prevent reset phenomenon caused by strong noise.

SCM of both upper computer and lower computer contains internal oscillator. However, as they cannot provide an accurate machine clock, external crystal should be used for replacement in the system. The selection of crystal oscillator frequency should be based on the practical situation. Generally, it should be within $10 \sim 15 \mathrm{MHz}$. The clock produced by crystal oscillator in such frequency 
range can form an accurate clock frequency in terms of SCM and influence the Baud rate of asynchronous receiver and transmitter in the system. In addition, compensation should be made for drifting generated in crystal oscillator frequency due to temperature change through capacitance ${ }^{[2]}$.

\section{Measuring module design}

The management system of iron phosphate-lithium power storage battery pack contains measuring module which is mainly divided into two parts. One part is located in the lower computer of the system and realizes the measurement of single battery voltage and temperature in work; the other part is located in the upper computer of the system and mainly measures the total current and voltage of battery pack with Hall sensor as technical support. As it has important meaning for the overall storage battery pack management system, parameters measured can influence the operation and control of power battery pack. Therefore, measuring module is the key to the success of management system design.

Design of measuring module of single battery voltage

Single battery voltage part in measuring module is important for reflecting the performance state of battery. It can display working environment state, driving force state and remaining capacity of battery etc. In the case of battery aging phenomenon, voltage and current values will change with the change of capacity. Measuring module will reflect battery capacity directly based on voltage value in different periods. For power storage battery pack of electric automobile, the main task of measuring module is to determine voltage parameters and evaluate the working condition of battery pack. Though the state of single batteries is consistent theoretically, all single batteries have differences. Therefore, there is a reason for the setting of single battery voltage measurement in measuring module, as shown in fig.3.

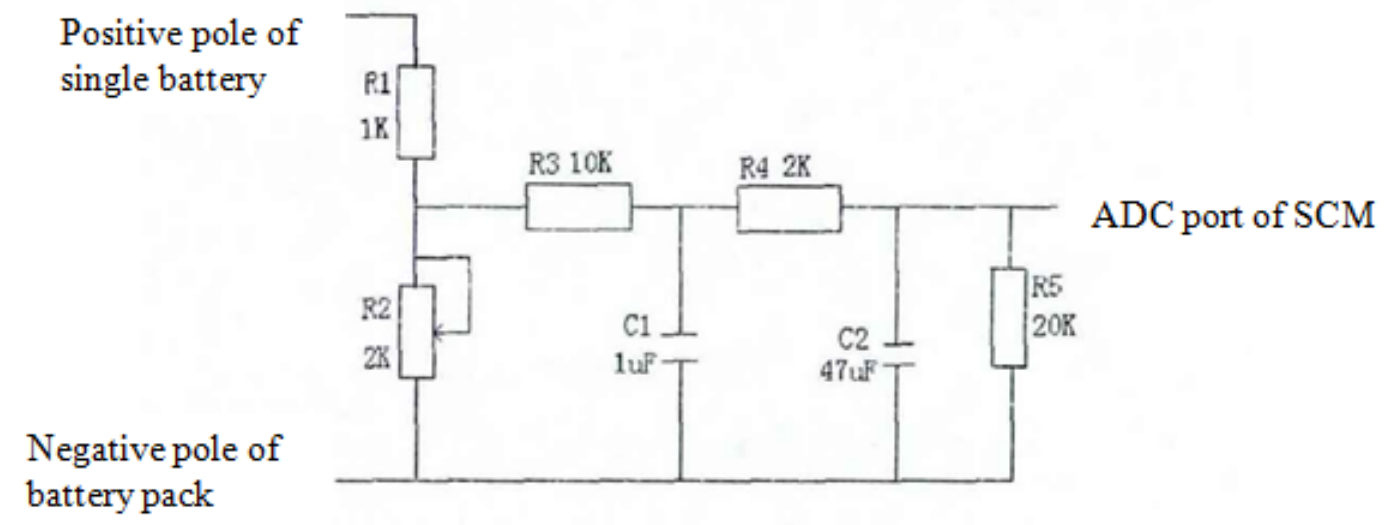

Fig.3 Schematic diagram of SCM single battery voltage signal processing circuit

As shown in fig. 3 above, single battery measuring module in the management system will collect voltage signals in a centralized way based on the standard of 16 single batteries in one group. As the total voltage of 16-battery pack will be high, it cannot be converted directly through SCM AD port. Instead, voltage signal processing should be conducted first. Generally, there are two solutions for voltage signal processing.

Solution 1: voltage reduction of circuit. When positive input end in system circuit is connected to positive pole of the measuring target single battery, negative input end should be connected to negative pole of the single battery in power battery pack. After partial pressure of fixed resistance R1 and rheostat $\mathrm{R} 2$, resistance values of $\mathrm{R} 1$ and $\mathrm{R} 2$ should be $1 \mathrm{~K} \Omega$ and $2 \mathrm{~K} \Omega$ respectively. For voltage value borne by the two resistances, rheostat R2 mainly makes resistance value adjustment. Then, three fixed resistances will conduct secondary partial pressure. Their resistance values are respectively $5 \mathrm{~K} \Omega, 3 \mathrm{~K} \Omega$ and $15 \mathrm{~K} \Omega$, i.e. R3, R4 and R5. Therefore, voltage signal value of single battery after voltage reduction of power battery pack can be inferred with formula:

$$
\mathrm{V}=\frac{\mathrm{R} 2}{R 1+R 2} \times \frac{R 5}{R 3+R 4+R 5} \times V_{0}
$$


Where $\mathrm{V}_{0}$ refers to voltage difference between the two poles of single battery. If it is expected to obtain an accurate voltage signal, voltage signal should be filtered based on capacitance C1 and C2, respectively involving primary and secondary filtering. Filtering aims at guaranteeing that SCM can always obtain a stable voltage signal.

Solution 2: voltage signal of single battery can be collected through non-contact collection with relay, e.g. semi-conductor relay. As high-performance economic-type semi-conductor relay chip is used, there is no problem in sensitivity and responsivity. Meanwhile, it is unnecessary to protect diode in the whole process and MOS driving power is not required.

On the whole, the two solutions have certain error in the implementation process. In particular, there is error in the resistance value used in the circuit in solution 1. For example, 16 step-down circuits corresponding to the battery pack composed of 16 single batteries have different step-down resistance ratios in the practical application process. Therefore, the problem of control difficulty will be encountered during the implementation of measuring work. When the negative pole of circuit is connected to the negative end of battery pack, mutual interference between voltage circuits will increase. This causes the reduction of signal accuracy in voltage reduction process of single battery. Relatively speaking, high sensitivity and responsivity in solution 2 will produce accurate battery voltage signal for battery pack chip due to the use of non-traditional non-contact voltage signal acquisition method. Therefore, the latter is selected for voltage signal processing in the system.

Design of measuring module of total voltage and current

Measuring module of total voltage and current is located in the upper computer of management system. For the convenience of measurement, the system in this paper adopts voltage signal acquisition circuit. As electric battery pack is composed of single batteries, each part of power battery pack has the same current on the whole. It is only necessary to measure its voltage and current values for once. In terms of the selection of measuring sensor, the system in this paper adopts Hall current sensor which can master the precision of total current measurement of electric battery pack well. It also provides non-contact measuring scheme. Measurement failure will not influence system work and meanwhile it has high safety and reliability.

In the early stage of design, total voltage signal and current signal of power battery pack should be subject to $\mathrm{AD}$ conversion first. The specific process is to transfer total voltage signal into normal voltage within the acceptable voltage scope through SCM port of step-down circuit. Total current signal is converted into voltage signal through Hall current sensor. In this system, the key to this running program processing is to achieve accurate reading of voltage signal jointly with hardware circuit and software program design. BCD code output and BUSY line control and count output are mainly adopted in the process of conversion of current into voltage, which can achieve high precision of 14-digit A/D conversion, as shown in fig.4.

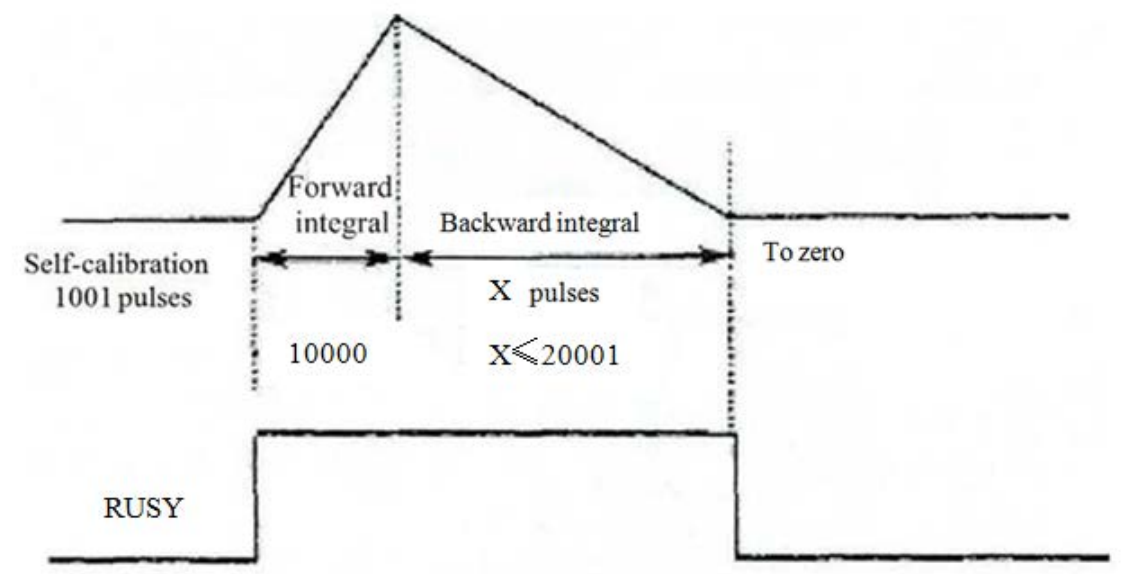

Fig.4 Sequence chart of BUSY line control of measuring module of power storage battery pack

Fig.4 shows BUSY line control sequence of measuring module in upper SCM. The increase of BUSY value will produce forward integral. On the contrary, integral will turn to zero and BUSY 
value will decrease greatly. In terms of counting time of control counter, BUSY line control sequence has a strong applicability.

$\pm 5 \mathrm{~V}$ power sources should be added to SCM for continuous power supply. $+5 \mathrm{~V}$ power source can be selected separately as SCM chip can be used for positive and negative conversion of $+5 \mathrm{~V}$ voltage source and polarity adjustment in the management system. In addition, SCM upper computer is used for providing clock frequency. It uses 14-digit binary asynchronous counter which can make count output and adjustment for the overall management system. Generally, Q4 counter output is adopted in the management system to keep crystal oscillator frequency between 4 and $8 \mathrm{MHz}^{[3]}$.

\section{Conclusion}

New energy electric automobile uses iron phosphate-lithium power battery for improving high-precision measurement and voltage and current conversion of its internal power battery pack management system and guaranteeing the accuracy of real-time data measurement. It can raise the alarm and inform the driver in the case of any problem of battery pack. This greatly improves the safety and stability of electric automobile and has high research value.

\section{References}

[1] Li Huiqi. Lithium Ion Power Battery Pack Management System Based on CAN Bus. Mechanical and Electrical Engineering Technology, 2007,36(1):81-82.

[2] Hu Yinquan. Study on Key Technologies of Power Battery Pack Management System. Chongqing University, 2013.56-60.

[3] Gao Jinchao. Design of Power Battery Pack Management System of Electric Automobile and SOC Estimation Based on Ampere-Hour Method. Tianjin University, 2013.20-27. 